\title{
Caste - An Evaluation of Evolution
}

\author{
Akash Chatterjee \\ Student Researcher \\ BA LLB (Hons.), IV Semester \\ Amity Law School \\ Amity University, Kolkata \\ India
}

\begin{abstract}
Caste - the most widely quoted term in respect to any kind of social relation is ironically the most seldom delved into. Partial and biased opinions about the discriminatory and redundancy of this social division has quite easily eclipsed its rational origin. As an evidence of history and a testimony in sociology, researched in the light of its origin and the impact that it has produced in society, caste is an interesting and relevant topic of research.
\end{abstract}

Keywords: Caste, Society, Super Ordination, Origin, Hierarchy, Relevance

\section{THE ORIGIN}

Classification and social categorization has always been the way of carrying out executive functions, smooth running of administration and a functional coexistence of diversely unrelated masses living together. Hence even society had to be segmentally stratified into castes, and from there on evolved caste based occupations, subsequently a rigidity did also arise making a sharp classification that simply became indissoluble, stringent and orthodox.

The Divine origin theory of castes suggests that the four castes emerged from the different parts of the AdiPurusha - Supreme God. The theory postulated that Brahmins were born from the head of God, Kshatriyas from the arms, vaishyas from the thighs and shudras from the feet. This became the most widely accepted and most socially accepted, prevalent theory and this also served as the basis for social gradation. The Brahmins naturally were given a super ordination over the other castes, and shudras were allotted to be the meanest position. This classification quite systematically categorized occupations -Brahmins were the people who dominated the social strata with the monopolistic knowledge of the Vedas, they used to perform the yagnas and offer ceremonial sacrifices as well. They were initiated with a sacred thread ceremony and enjoyed being the privileged class. Kshatriyas were in charge of protecting the masses, they were to assume kingship and rule the kingdom as administrators, be skilled in the art of warfare and wield the royal dandaas the punishment and regulating mechanism of the code of conduct of the people. Vashyas were the mercantile community who were supposed to take care of all forms of business, trade and generate income for the country or society as a whole. Shudras were the menial class who worked and assisted the other upper castes in their day to day activities. They were required to serve, obey and abide by the orders of the higher castes. Although the divine origin theory did not designate an inferior status to them, rather they originated from the feet was a symbol of representing that the shudras were close to the earth or the bhumi, the interpretations changed thereafter. This was the caste which became the most exploited, tortured and denied with successive passage of time.

Very ideally, this was a closely knit economic system which was a composition of strong self sufficient units that were complimentary to one another and helped in the smooth functioning of the economic order.

\section{BOUNDARIES}

While at one hand it can be possibly claimed that caste system acted as a classifying system, on the other hand it created indelible boundaries that could not be crossed over and which restricted interactions at the same time. This was primarily due to the nature of the occupations performed by the people of the caste groups and second of all the inherent desire of respective caste groups to preserve their common identity. The initiation of the system might have created sectors of economy and restricted competition to caste based employment, but it did not remain so simple after all. The sectors became boundaries and these boundaries developed into social barriers.

It can also be noted that castes served as social groups in the society. People have their inherent tendencies to group and belong on common grounds and mutual preferences, which in a way knit them up as a group together and led to a common shared identity for the members of the caste. This common identity slowly developed into rigid ethnocentrism and subsequently the boundaries of caste crystallised into permanent divisions.These divisions served as the breeding grounds of a social division which shaped a new mould in the society.

With progress of time and when the process of Aryanisation was expanding rapidly over the Indian subcontinent, ethnic or ingenious people were at first socially ostracised and pushed beyond the precincts of the Aryavrata, with minimal social interaction with them, but this trend changed soon. As chiefs began expanding their dominions, chiefdoms began to develop into kingdoms. Smaller clans and tribal units, dasas and dasyus, were conducted into the social fold. As they entered into the caste structure of the Hindus or essentially the Aryans, a new fifth caste emerged called the "panchamas" or the outcastes. They obtained a place in the mainstream society but were in a condition even worse than the Shudras. This inclusion or rather ironic inclusion of a new caste showed a new trend in the social dynamics. This gave a chance for the ostracised class to get involved but at the cost of their dignity. While on one hand this shows inclusivity in the existing system, it also points out that acceptance of a caste in a system was not on the basis of their occupation, rather the familiarity. This can be held from the point of view of social 
distance. While the Brahmins, kshatriyas and the vaishyas were segments of Aryan society and although in a hierarchy still they were involved in continuous interactions and were awarded the designation of Dvija or twice born and associated with an initiation ceremony. While at one hand upanayan or the wearing of sacred thread was a spiritual aspect of life, at the same time, it was a poignant contrast in dynamic social mechanism whereby the lower castes were excluded. With the beginning being this, quite naturally opportunities, wealth and prosperity not only varied on economic lines but also on the distinctions of upper and lower castes. While at one hand it may be a tool for upper castes to preserve their culture against the inflow of indigenous people, on the other hand the economic equation of serving and served classes. This boundary that was essentially created was not very rigid and there was scope for mobility at the same time, was inherently present although not explicitly mentioned. Mobility was specified as people could change their occupations in the line of attaining higher social status and at the same time engaging in a different economic activity based on individual desire or situational demand. When this mobility allowed change of occupations and the related caste system at the same time, the system was not so rigid. AS time passed, a social classificatory system became a social segmentory mechanism which kept the castes in their respective chosen ambits and apparently sustained the social order.

This social order was first challenged by the incoming hordes of invaders - Hunas, sakas, yavanas collectively often referred to as Mlecchas. When the social fold began integrating people of foreign culture, a new dynamic developed and in which we find the roots of ethnocentrism and xenophobia bearing a direct relation with caste.

\section{RESTRICTIONS}

Although it may seem derogatory and orthodox to have restrictions on food habits especially when it prohibits interaction between the castes, but at the same time society has to be evaluated from a non judgemental view each time. Along with food habits, marriage was hedged to a system of endogamy - marrying within the caste groups and any exogamous marriage was unacceptable. A person of higher caste was supposed to maintain a distance from the lower castes with respect to certain criteria. In respect of the food habits - there are classifications as in kaccha food, pakka food, raw materials. While pakka food is food cooked with ghee or oil, kaccha food is boiled essentially and raw materials include raw rice or fruits. A Brahmin was not supposed to accept pakka food from any lower castes and even in case of kaccha food there were restrictions, while raw items could be easily given and taken. One significant feature that is noteworthy is that, while Kshatriyas and Vaishyas both were inferior to Brahmins, but Shudras and the outcastes were often equated and subject to yet harder prohibitions. This can be explained by the theory of familiarity, as the upper three castes represented the occupations of the Aryan tribe and as they settled, these three occupations oriented people into corresponding castes of significance therein excluding the shudras and the outcastes who had the importance of being petty labour force or manpower.

Food restrictions were followed by preventions on eating together by the higher or the lower castes and subsequently separation of wells from which water was to be drawn for domestic uses. This quickly engulfed the society into a segmented and exclusively separated existence where caste groups became myopic sectors thereby dividing the greater society into mutually exclusive compartments. Kitchen, temple and wells were the first arenas to be completely segregated. With the influx of the tribal and the foreign mlecchas into the Hindu caste fold, the xenophobic instincts of Brahmins and the upper castes took the form of a poignant notion of " purity and pollution ". This is an ubiquitous phenomenon that got itself expressed, as whenever there are cultural interactions, ideas and concepts of superiority and inferiority complex develop. In this case the Hindu society toughened its restrictions on caste boundaries as the root to belonging in the borders of the caste fold was open and invited influx. Hence upper castes in an attempt to save their privileged position, maintained that interacting with the lower castes would be pollution or maligning their purity. In this way, talking, mixing, touching a lower caste meant losing of purity and social boycott as well. In case of wells, lower castes were forbidden to use and in case of temples there entry was restricted in many cases. This may be a regressive social set up but from a particular situational point of view, it was quite a natural reaction to the ongoing socio cultural intermixing. On broader level, different caste based economic groups had different lifestyles and standards of hygiene, hence restricting intermixing would evade health issues as a natural consequence thereof, because a person of affluent class would always have standards of quality and hygiene starkly different from a relatively poorer lower caste. Secondly comes the question of marriage which completely integrates two families, so in the prevailing social set up, endogamous marriages was given the preference to once again preserve the group culture.

With the advent of Islam in India, the prevailing Hindu society encountered a different culture and religion altogether, and with a new religion the xenophobic instincts took over the prevailing upper classes and renewed restrictions came to the fore. This time the Brahmins also felt the threat of conversion and the threat of their own culture system being held at ransom by the Islam Sultan. As the Muslim population expanded, intermixing started and slowly with more liberal Islam Sultans, a peaceful coexistence developed.

\section{VIEWPOINTS}

Orientalism upheld that caste was essentially an economic categorisation which stifled its roots slowly into the fabric of society. From the Missionaries, Christian ambassadors of Religion, caste was found to be embedded into the Hindu religious system. From the administrative point of view, Brahmins became the law makers who interpreted the scriptures and preserved the right to teach VEDAS to the other people, and that caste was essentially a means of political control by classificatory segregation of a huge population engaged in vital economic activities.

Risely primarily took the anthropological approach and attempted to classify caste on models of race, racial features and associated characteristics which to some extent yielded positive confirmatory results as generations of endogamy led to it, but making it a theory of its origin would be neglecting the social dynamics of India. Risely's conception was modelled on the Orientalist theory of Aryanisation and that castes were actually differences of superior Aryans over the inferior Indigenous people as a result of the political subjugation.

\section{BRITISH INTERVENTION}

The most significant development which caste system faced in its history was during the period of British rule in India. As 
the British did not recognise caste system and caste boundaries, so it essentially tried to integrate the society. Some areas where it was witnessed were in army and in train compartments or other services under the British government. In these places, castes were brought to interact with each other. This was interpreted in twin ways - first, that the liberal western ideals of British were assimilated into the common folk, as held by the liberal school of thought, second, it was the British who brought the caste issu3e to the fore by deliberately making them interact and in doing so, they tried to sabotage the common identity and shared unity of Hindus as a formidable force against them.

\section{CHALLENGING THE SYSTEM, NEW WINDS}

Although caste remained as a vital distinction, segregating mechanism in the society, but there were always winds of change, when there was sheer defiance to this system. Firstly mobility started with the process of Sanskritisation which M.N.Srinivas has explained in which a person of lower caste moves towards the upper castes by adopting their rites and rituals. Next there were Bhakti and Sufi movements in different parts of the country, in which emphasis was simply on devotion allowing everyone to have their own right to worship and the liberty to worship, simplifying religion to its very core. With the freedom movement in the 19th century, different castes and social groups came together, uniting for a common cause and this led to a defying of caste for greater good. Western liberal floodgates of thought and conceptions opened up in front of the people of India and the educated youth felt the need to reject the system at the same time. Jyotirao Phule was adamant in defying the caste based oppression and mobilising bonds of unity, instilling pride amongst the depressed castes.

However the biggest change came with B.R.Ambedkar and his policy of reservations on the basis of castes so that the lower castes who have suffered centuries of neglect can be pulled up at par with the other castes. 1979 Mandal Commission slated to recognise some castes as Scheduled Castes and Tribes, thereby entitling them to reservations in public sectors and educational institutions, although it was a step ahead, but today even this step is being misutilised into wrongful gains by people entitled to reservations.

\section{POLITICISING AND SOCIALISING}

Among the various other effects that the institution of caste has on society, perhaps the most significant in today's aspect shall be its politicising nature- the way it has aided politics to be shaped and developed on caste based grounds. As on one hand, Indian political scenario developed as the biggest democracy in the world, on the other hand, it got scarred and marred with caste based divisive forces that in turn evolved into a secondary socialising force as well. Now as an agent of socialisation, caste serves as an identity that is rigid and affiliates an identity mark to its members or the ones who bear it.

\section{CONCLUSION}

The Conclusion to this topic cannot be simple, but there can always be a food for thought out of this piece of research That is the question of Dynamicity and development in each social system or mechanism. Since the only thing static in society is change, hence every social aspect undergoes a change. Caste as developed was a vital mode of social control which soon lost its significance into an orthodox practice, similarly any rule or law on society thereof should be dynamic as society churns out different consequences on the same aspects revolving around in its ambit, and caste in this sense is definitely a product of society envisioned in the perspective of history.

\section{BIBLIOGRAPHY}

1. Sociology - D.C. Bhattacharya

2. Sociology of Indian Society - C.N. Shankar Rao

3. History of Modern India - Ishita Bannerjee

4. Principles of Sociology - C.N Shankar Rao 